\title{
An Economic Approach for Children with Chronic Ventilation Support
}

\author{
Aroonwan Preutthipan - Malinee Nugboon • \\ Thitida Chaisupamongkollarp • Teeradej Kuptanon • \\ Harutai Kamalaporn · Anchalee Leejakpai
}

Published online: 28 December 2013

(C) Springer Science + Business Media New York 2013

\begin{abstract}
The number of children requiring long-term ventilation support is increasing in many countries around the world. Children benefit from being mechanically ventilated at home rather than staying in the hospital for a longer period of time. Here, we have reviewed the related literatures and guidelines on pediatric home mechanical ventilation and shared our experience in Thailand, where there is no federal or insurance coverage for home care. An economic approach has been taken that includes using less expensive ventilators, training non-professional family caregivers, and seeking funding resources. We also report on the favorable outcome of a program we started in 1995. Of 148 children, $95(64.2 \%)$ have used noninvasive ventilators, $128(86.5 \%)$ survive, $20(13.5 \%)$ were weaned
\end{abstract}

\footnotetext{
A. Preutthipan $(\bowtie) \cdot$ T. Kuptanon · H. Kamalaporn ·

A. Leejakpai

Division of Pediatric Pulmonology, Department of Pediatrics,

Ramathibodi Hospital Sleep Disorder Center, Faculty of

Medicine, Ramathibodi Hospital, Bangkok 10400, Thailand

e-mail: aroonwan.pre@mahidol.ac.th

T. Kuptanon

e-mail: kteeradej@gmail.com

H. Kamalaporn

e-mail: doctoroom@yahoo.com

A. Leejakpai

e-mail: leejakpai@hotmail.com

M. Nugboon - T. Chaisupamongkollarp

Department of Nursing, Faculty of Medicine, Ramathibodi

Hospital, Bangkok 10400, Thailand

e-mail: malinee_nugboon@yahoo.co.th

T. Chaisupamongkollarp

e-mail: thitida.cha@mahidol.ac.th
}

off, only four (2.7\%) died unexpectedly. We hope that this model approach may be useful in some areas with similar difficulties.

Keywords Chronic respiratory failure $\cdot$ Respiratory insufficiency · Home mechanical ventilation · Long-term mechanical ventilator $\cdot$ BPAP $\cdot$ CPAP

\section{Introduction}

Long-term ventilatory support is an essential treatment for children with chronic respiratory failure. Advances in mechanical ventilator technology and respiratory care have resulted in increased survival and prolonged life expectancy in these children $[1 \bullet \cdot, 2,3]$. In the past, patients who still required ventilatory support had to be hospitalized for prolonged periods of time, until they passed away or were able to be weaned from mechanical ventilators and return home. This resulted in lengthy and costly hospital stays, and use of beds that could be available for other needy patients with acute illnesses. Being away from a home environment for a long time can also have a negative impact on a child's growth and development [4]. Some children acquire nosocomial infections with multiple-drugresistant organisms during their hospital stays, requiring more expensive, stronger antibiotics to treat ongoing, serious episodes of infection [5].

\section{Children Prefer to Go Home}

Sending children with chronic respiratory failure to live with their families at their own homes has been shown to 
be the most cost effective measure $[6 \bullet, 7,8]$. Home-based care is less expensive than in-hospital care if home nursing service is not taken into account [7, 9]. It is generally accepted that a home environment is preferable to hospital or intensive care for a child who needs chronic ventilator support [10•]. Home environments enhance quality of living, unite or reunite children with their communities, and thus, allow them to reach their full potential as family and community members [11]. The benefits of home care are more obvious in children with neuromuscular weakness $[1 \bullet \bullet, 12,13]$. It has been shown that children with spinal cord injury and neuromuscular conditions show improvement in their qualities of life and lower morbidities and mortalities after initiating home mechanical ventilation $[13,14]$.

Increasing Incidence of Chronic Ventilator Support in Children

Although the exact number of children who are dependent on home mechanical ventilation worldwide is not available, many centers have reported exponentially growing numbers of patients being discharged to their homes with chronic ventilatory support $[1 \bullet \bullet, 6 \bullet, 15,16]$. In Canada, there was more than a two-fold and five-fold increase in the number of invasive and noninvasive initiations of home ventilation in children during 2001-2010, as compared to during 1991-2000, respectively [1••]. A survey done in the United Kingdom in 1990 identified only nine children on home mechanical ventilation. The number then increased to 93 in 1991 and 859 in 1998 [17••]. Another survey report from Massachusetts in the USA documented 14 children with long-term ventilator dependence in 1980 [18]. Subsequently, the number increased significantly, to 70 and 77 in 1987 and 1990 [19], and further to 197 in 2005 [20]. Similar findings have been reported around the world, such as Australia [21], Italy [22], Japan [23], New Zealand [24], and the USA [25].

The increasing trend of pediatric home mechanical ventilation can be explained by a variety of reasons. Equipment technology has improved, especially in the intensive care unit. More patients that would have died in the past can survive and live longer, but still depend on long-term ventilator support. The development in respiratory support technology has broadened the composition of home-care equipment modalities, which are more suitable, more portable and more user friendly with appropriate alarm features. The advancement in noninvasive ventilation was a major contribution to the expansion of home support, especially for children with congenital and acquired neuromuscular weakness $[1 \bullet \bullet, 10 \bullet, 20]$. Technological progression to detect nocturnal hypoventilation by either overnight polysomnography or end-tidal $\mathrm{CO}_{2}$ monitoring during sleep leads to early initiation of home ventilation in children with neurological problems, and chronic and restrictive lung disorders.

Our hospital, which is a teaching university hospital in a middle-income country, started a program for home mechanical ventilation in children in 1995 [26]. We were honored to receive the Governors Community Service Award from the American College of Chest Physicians in 2003. Up until now, 148 children have received home mechanical ventilation under our long-term care. Fifty three children $(35.8 \%)$ were invasively ventilated via a tracheostomy and $95(64.2 \%)$ received noninvasive mechanical ventilation. The number of children on home ventilation was considerably increased over the last decade (see Fig. 1). The mean age at the time of initiation of invasive ventilation was $4.6 \pm 5.0$ years (range 0.3-19 years) and noninvasive ventilation was $9.1 \pm 4.4$ years (range $0.4-17.8$ years). The longest duration of home mechanical ventilation was 18 years. As the mortality rate of our program is 20 out of a total $148(13.5 \%)$, and $20(13.5 \%)$ other children were able to be weaned off, the number of our population is cumulatively growing. There have also been positive changes in the attitudes of Thai families toward home care for technologydependent children. After we were able to show the benefits and good outcomes of the first few patients we sent home, we gained more cooperation and willingness from families of the succeeding children with chronic respiratory failure. We are able to convince the families that home ventilation is feasible and that most children can go home safely. Another reason that the number has grown is the shortage of beds available in our hospital. The patients may come with acute illnesses from other organ systems, but end up with chronic respiratory failure. Our pulmonary team is mainly responsible for assisting such patients to be discharged from the hospital as soon as possible. With recognition on the accomplishment of our program, more children requiring long-term ventilation support have been referred to us, thus resulting in an increasing number of our home ventilation patients.

\section{Underlying Conditions}

The causes of chronic respiratory failure requiring longterm mechanical ventilation are classified according to pathophysiological approach, such as: neuromuscular weakness, failure of breathing control, airway disorders, restrictive disorders due to kyphoscoliosis or diaphragmatic problems, chronic lungs, obstructive sleep apnea, and obesity hypoventilation syndrome.

A national survey done in Italy in 2011 identified 362 children receiving home mechanical ventilation, among whom the most frequent diagnostic categories reported were neuromuscular disorder (49\%), lung and upper respiratory tract diseases (18\%), hypoxic ischemic encephalopathy 
Fig. 1 The number of children receiving home mechanical ventilation between 1995 and 2013

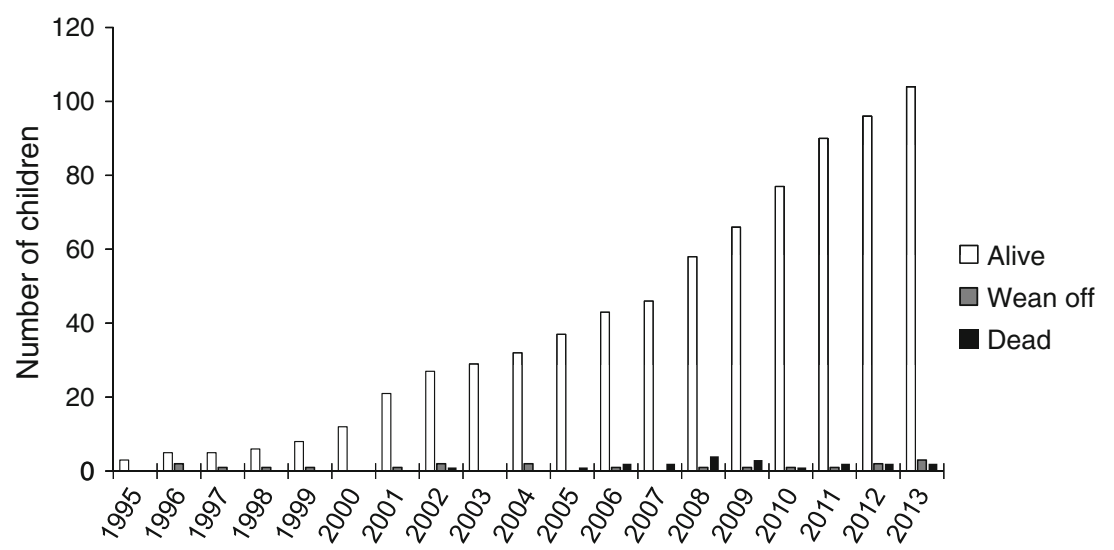

(13\%), and abnormal ventilation control (12\%) [22]. Another report from Taiwan similarly found that neurologic/ neuromuscular diseases were the most common underlying disorders in children requiring long-term mechanical ventilation, followed by airway/lung dysfunction [27]. Neuromuscular disorders were again found to be the principal diagnostic categories leading to the requirement of longterm mechanical ventilation in Canadian children [28]. In the UK, the two common underlying disorders were airway pathology (tracheobronchomalacia and obstructive sleep apnea) and neuromuscular disease [29].

Table 1 lists the main causes of chronic respiratory failure in our population. Apart from obstructive sleep apnea $(n=71,48 \%)$, the main reason for ventilation was neuromuscular weakness $(n=22,15 \%)$. The diagnoses in the group of neuromuscular weakness included spinal muscular atrophy $(n=8)$, myopathy $(n=3)$, myasthenia gravis $(n=3)$, etc. For airway disorders, there were cases of airway malacia $(n=14)$, bronchiectasis $(n=2)$, etc. Our findings do not significantly differ from other reports $[1 \bullet \cdot, 10 \bullet, 22,27,28,30]$, except that obstructive sleep apnea was found to be the majority cause in our population. This can be explained by the fact that we are the first hospital and referral center in Thailand providing standardized, full polysomnography for children. It should be noted that many of our child patients have multiple other conditions affecting their well-being, such as cardiac disease, seizure disorders, endocrine disorders, and so on. These comorbidities make their care even more complex.

\section{Ventilation Strategy}

The goal of home mechanical ventilation is to correct chronic respiratory failure, to allow children to reach their developmental potential [31]. The strategy of home mechanical ventilation is classified into invasive and noninvasive methods. Choosing either method depends upon diagnosis, disease severity, daily hours of mechanical
Table 1 The etiology of the need for home mechanical ventilation and type of support

\begin{tabular}{llll}
\hline Etiology & $\begin{array}{l}\text { Total } \\
(n=148)\end{array}$ & $\begin{array}{l}\text { Noninvasive } \\
\text { ventilation }\end{array}$ & $\begin{array}{l}\text { Invasive } \\
\text { ventilation }\end{array}$ \\
\hline Obstructive sleep apnea & 71 & 71 & \\
Neuromuscular weakness & $\begin{array}{l}(48 \%) \\
\text { Failure of breathing control }\end{array}$ & 11 & 11 \\
Airway problems & $(12 \%)$ & 3 & 15 \\
Chronic lungs & 18 & 3 & 15 \\
Kyphoscoliosis & $(12 \%)$ & & \\
Diaphragm problems & 7 & 3 & 4 \\
Heart failure & $(5 \%)$ & & \\
& 5 & 5 & 3 \\
\hline & $(3 \%)$ & & 2 \\
\hline
\end{tabular}

ventilation needed, patients' cooperation, amount of secretion, experience of physicians and nurses, and the availability of ventilators along with their accessories.

Noninvasive ventilation has a lot more advantages over invasive ventilation. In patients who need only nighttime home ventilation, it is more convenient to use noninvasive ventilation at night and avoid tracheostomy during the day, keeping their daily lives similar to those of healthy individuals. Without tracheostomy, there are far fewer related complications such as tracheitis and bleeding. The presence of a tracheostomy tube on the neck also impacts negatively on patients' daily living and social life. Caregivers need to have more essential skills to take care of a tracheostomy than they do with just a mask and interface. Recent widespread distribution of mask interfaces designed for 
pediatric patients has made noninvasive ventilation more practical in children.

For the above reasons, noninvasive ventilation should be considered first for children with chronic respiratory insufficiencies secondary to a variety of diseases, including neuromuscular disease, chest wall restriction (bony abnormalities, etc.), chronic lung disease, upper airway obstruction, obstructive sleep apnea not improved after adenotonsillectomy, and obesity hypoventilation [32]. Invasive ventilation is used only when the patients show evidence of either failure to adequately ventilate with noninvasive ventilation, failure to tolerate mask ventilation, bulbar dysfunction with a high risk of ongoing aspiration, or a high level of dependence on assisted ventilation (>16 h/day) [31-33].

A report on 40 children with neuromusculoskeletal disease aged 9 months to 16 years who used noninvasive ventilation only at night showed a significant improvement in nocturnal and diurnal arterial blood gas tensions [34]. Nocturnal noninvasive ventilation can correct nocturnal hypoventilation, reduce nocturnal hypercapnia, improve respiratory muscle function, and reduce the workload of the respiratory system, therefor leading to an improvement in daytime arterial blood gas tension during awake spontaneous breathing [35].

\section{Ventilator Choices}

\section{Noninvasive Mechanical Ventilator Through Masks}

There are two types of ventilators: continuous positive airway pressure (CPAP) and bi-level positive pressure (BPAP). They generate high air-flow to compensate for leaks around the masks in order to reach the pre-set pressure [35]. They usually have a single-tube circuit with a passive exhalation port incorporated into the circuit near the patient, or into the interface [35, 36]. Mask fit is the most important factor for success. The mask should ensure comfort and fit while minimizing leak [17••]. A poorly fitting mask interface will decrease the clinical effectiveness of treatment through leaking, and may impact on adherence. Excessive leaking can impact on sleep quality, patient-ventilator synchrony, and the amount of effective ventilation delivered to the patient [37, 38]. Chinstraps have been shown to reduce mouth leak in some patients during nasal mask ventilation [39]. A full-face mask can also be chosen to minimize leak in some patients $[33,39]$.

A CPAP machine is used to distend the upper airway in obstructive sleep apnea patients. The BPAP machine is used to provide ventilator support for patients with alveolar hypoventilation. The levels of inspiratory and expiratory positive airway pressure are adjusted to provide effective ventilation. The BPAP ventilator can be set in the spontaneous mode (the patient cycles the device), the spontaneous timed mode (a back-up rate and inspiratory time can be set in case the patient does not trigger the device) and the timed mode (inspiratory time and respiratory rate are fixed) $[40 \bullet \cdot]$

\section{Invasive Mechanical Ventilator Via Tracheostomy}

A number of modern home ventilators are available that offer different settings including volume-targeted and pressure-targeted, in assisted-controlled or controlled modes, as well as with pressure support. The choice of mode should be individualized depending on patient comfort and underlying conditions. The standard home ventilators must be portable, have internal batteries, and alarms to detect disconnection and tracheostomy tube blockage [17०0]. It should be noted that the price of an invasive home ventilator is approximately $2-5$-fold that of noninvasive BPAP ventilators.

Formal titration of settings using either polysomnography or cardiopulmonary monitoring (including pulse oximeter, capnometry, patient flow, chest wall movement and machine output) can identify optimum settings and possible problems with ventilator support during sleep [37, $40 \bullet$. By monitoring patients first under polysomnography, we can adjust inspiratory and expiratory pressure, back-up rate, inspiratory time, and trigger sensitivity, and detect leaks. The goal is to achieve adequate ventilation and oxygenation, the utmost comfort for the patient, and good quality of sleep with minimal arousals $[40 \bullet \bullet]$. In order to be eligible for discharge, the child's medical conditions (either respiratory or other organ systems) and ventilator support requirements should be stable without any changes for approximately a month or so [32, 41].

\section{Our Experience with Home Mechanical Ventilators}

Because obstructive sleep apnea was the predominant cause in our group, noninvasive ventilation was found to be the most common ventilation strategy used $(n=95$, $64.2 \%)$. Even when obstructive sleep apnea is excluded, noninvasive ventilators were initially selected more often than invasive ventilators, especially over the last 5 years.

The youngest age of our patients successfully using noninvasive ventilator was 4 months old, at a body weight of $6 \mathrm{~kg}$. The patient had developed cyanosis since birth, and polysomnographic findings were compatible with congenital central hypoventilation syndrome, which showed markedly more hypoventilation in non-rapid-eye-movement (non-REM) sleep. We recommended that he have a tracheostomy, but his family disagreed; the parents insisted on using a noninvasive strategy. They hired a lay person to manually keep a full-face mask on the baby's face all 
through the night while he was asleep. They have been using this technique to ensure adequate ventilation. At present he is 8 years old, thriving, and developing appropriately for age.

In Thailand, there is neither government funding nor any insurance coverage for home mechanical ventilation. All expenses are directly borne by the family. This, standard invasive ventilators were too expensive for most of our patients. The choice of ventilator is determined firstly by the price, and secondly by level of safety [26]. To cut down on expense, BPAP and CPAP machines have been found to be more suitable for this difficult situation. Among 53 children using invasive ventilators, $25(47 \%)$ have used BPAP via tracheostomy, and 15 (28\%) have used CPAP via tracheostomy. Only the families of $13(25 \%)$ could afford to buy standard invasive ventilators. As a result, BPAP and CPAP machines are the most common types of equipment that we have been using. In our experience, these devices are effective in both noninvasive and invasive mechanical ventilation. They are durable, lasting 10 years at maximum and, more importantly, less expensive. No complications have occurred so far.

Most of our patients underwent polysomnography to ensure the most appropriate setting and safety. Once a good tolerance to bedside titration is reached, a polysomnographic titration is performed. This requires a tremendous amount of overnight work by experienced sleep technologists, supervised by pediatric pulmonologists.

\section{Funding}

The levels of financial support for at-home care for children on long-term ventilator support are highly variable across the world. In the USA, home healthcare is generally paid for by Medicaid, Medicare, long-term insurance, or occasionally with the patient's own resources [42]. In addition to the ventilators and accessories, home healthcare professionals are also provided. Professionals include licensed practical nurses, registered nurses, physical and occupational therapists, etc [42]. In the UK, a wide range of home healthcare services are funded by the NHS, private medical insurance or through self-funding for "top up" treatment [43]. In Australia and New Zealand, there remains a discrepancy in resource provision for children on home ventilator support throughout the country [6•].

Thailand is considered to be one of the lower-middleincome countries. Healthcare services in our country have been delivered mainly by the government. Universal coverage reform was introduced in 2001. Since then, healthcare is provided through three programs: the civil service welfare system for civil servants and their families, social security for private employees, and the Universal Coverage scheme that is theoretically available to all other Thai nationals. People joining the scheme receive a gold card, which allows them to access services in their health district, and, if necessary, be referred for specialist treatment elsewhere [44].

Unfortunately, home ventilation is not included in the lists of any programs described above. Patients have the right to stay in the government hospital if they still need ventilator support, but none of the private health insurance providers offer coverage for home care. If patients want to go home, their family is responsible for all expenses that may occur. The cost of equipment, supplies, and caregivers must be met by the family themselves. A number of patients whose conditions are suitable for home care still have to undergo unnecessary long-term hospitalization due to this lack of family resources. The feasibility of home care depends very much on the family's resources and their ability to cope with ensuing problems [26]. This is the main reason why BPAP and CPAP machines have been used most often among the children in our study. Fortunately, 33 $(22.3 \%)$ of our patients received ventilators donated by the Thai royal family, charitable organizations in Thailand and the USA, and by well-to-do individuals in the Thai society. Our team and the patients are always most grateful to all who have supported our program. Without this support, it would be nearly impossible to send these ventilatordependent children back home.

\section{Caregivers and Training}

The clinical practice guideline of the American Association of Respiratory Care for long-term, invasive home ventilation indicates that the caregivers must be credentialed healthcare professionals (RRT, CRT, RN) and/or licensed practitioners with documented knowledge. However, lay caregivers (family members, personal care attendants, non-credentialed healthcare personnel such as nurse's aides) can be taught tasks and techniques of care for a specific ventilator-assisted individual [45]. The Canadian Thoracic Society's clinical practice guideline on home mechanical ventilation indicates that caregivers should be educated and trained according to the specific needs of each patient [46*0]. In an evaluation of a respiratory therapist-driven family education program for caregivers of children on home mechanical ventilation, a comprehensive program demonstrated a positive impact in the performance and satisfaction of the caregivers [47].

Caregivers need to be trained in using, cleaning, and caring for the ventilators and accessories, basic trouble shooting skills, emergency problem solving, understanding alarms and corrective measures, and tracheostomy care, as well as basic life support $[37,48]$. In addition, they need to be trained to competently manage airway secretions, either by suctioning through a tracheostomy or by using manual and/or mechanical cough assist techniques, in patients with neuromuscular weakness who are on noninvasive ventilation. Their skills need to be reassessed periodically [37]. 
Assuming the responsibility for the care and management of ventilator-dependent patients is a life-altering event for most families and caregivers. The parental responsibility was found in some studies to be highly stressful and sometimes overwhelming [49-51].

In our country, where the cost of home care is directly charged to the family, it is impossible to have healthcare professionals (RRT, CRT, RN) and/or licensed practitioners as caregivers at home. We strongly believe that in order to assist complicated children to live at home, the most suitable persons to be trained as caregivers are the ones who really love them. Among the 53 children that we sent home with invasive home mechanical ventilation, 35 (66\%) of the primary caregivers were parents, nine $(17 \%)$ were relatives, and nine $(17 \%)$ were home nurse aids. All of them are non-medical professionals.

One advantage of Thai culture in this situation is the extended family setting, in which two or three generations live together in the same house. Either parent or other family members have all been selected and trained to be caregivers [26]. Experience for more than 15 years has taught us that the level of the caregiver's education is not as important as dedication. Commitment, motivation, and preparation from patients' families and caregivers are crucial for a successful transition to home [46••].

We are lucky to have devoted respiratory nurses and home visiting nurses working together with pediatric pulmonologists [26]. As respiratory therapist professionals do not exist in Thailand, respiratory nurses take on their role to train lay people to be able to take care of their mechanically-ventilated children at home. They also work as nurse coordinators, discharge planners, social workers, and so on. Teaching and training on the care of ventilated children is a gradual process that requires practice and repetition. Initially, it is very stressful due to the huge learning curve required to care for the child and to maintain the equipment safely. More time and experience subsequently reduce the involved stress. Once competence is gained, the parents are able to advocate for their child to get appropriate treatment [52]. They are also trained to know their limits, so that they seek help when necessary [17••]. The family can call respiratory nurses for help $24 \mathrm{~h}$ a day whenever any problems occur. When the children go home, our home visiting nurses go to see their home, in the beginning usually once a week, to supervise the caregivers and coordinate with the hospital team [26].

\section{Outcome}

Compared to adults, children with chronic respiratory failure have better prognosis. It was shown that some of the children outgrew their need for home ventilator support when they were older $[15,53]$. The long-term survival rates for children are influenced primarily by the clinical course of the underlying disease. As a general principle, a better outcome is usually observed in cases where the underlying disease is reversible, such as BPD, compared to the outcome of cases with progressive disorders, such as progressive neurologic disorders [31]. In the UK, the 5-year survival rate of noninvasive and invasive home ventilation was reported to be $94 \%$, and $21 \%$ were able to discontinue respiratory support at 5 years [28]. Patients with neuromuscular disease were less likely to discontinue support than other patients [28]. In the USA, the 5-year survival rate of only invasive home ventilation was reported to be $80 \%$, with $24 \%$ discontinuing home ventilation. Thirty-four percent of the associated deaths was due to progression of underlying conditions, whereas $49 \%$ were from unexpected causes [7].

From 1995 to 2013, our team has cared for 148 children and young adults receiving full- or part-time home ventilator support. Of these, 114 patients $(77 \%)$ remain alive and are still on home mechanical ventilation. Twenty patients (13.5\%) were liberated from home mechanical ventilation, and 15 of the 20 liberated patients $(75 \%)$ were weaned within 2 years of initiation. One patient with poliomyelitis was weaned to noninvasive ventilator support. Twenty patients $(13.5 \%)$ died. Progression of underlying conditions accounted for $16(80 \%)$ of the deaths; four $(20 \%)$ of the deaths were unexpected. The causes of the unexpected deaths were obesity-hypoventilation syndrome with severe pulmonary hypertension $(n=2)$, massive bleeding through tracheostomy $(n=1)$, and diarrhea and sepsis $(n=1)$. No deaths were caused by ventilator malfunction or were related to caregiver errors. Nineteen patients $(95 \%)$ died in hospital. Only one patient $(5 \%)$ died at home.

\section{Conclusion}

The prevalence of children with chronic ventilator support being cared for at home is increasing worldwide. We have shared our practice and experience in caring for such children with invasive and noninvasive home mechanical ventilation. The noninvasive method is becoming more popular among children with chronic respiratory insufficiency. With limitation in financial support, simple and inexpensive ventilators are used and parents are serving as caregivers. We do hope that our model approach may be useful for other countries having the same difficult situation.

Acknowledgments We gratefully acknowledge Varangkana Lamsam and family for their gracious, continuous long-term funding support to our underprivileged children. We thank Jongrak Utrarachkit, Jeeraporn Pongsasanongkul, Porntip Tachanives, Jarinya Prempreungves, and Wannapa Yensirikul for their extraordinary effort in caring for the patients. 
Disclosure Aroonwan Preutthipan, Malinee Nugboon, Thitida Chaisupamongkollarp, Teeradej Kuptanon, Harutai Kamalaporn, and Anchalee Leejakpai declare that they have no conflict of interest.

Human and Animal Rights and Informed Consent This article does not contain any studies with human or animal subjects performed by any of the authors.

\section{References}

Papers of particular interest, published recently, have been highlighted as:

- Of importance

•- Of major importance

1. • Amin R, Sayal P, Syed F, Chaves A, Moraes TJ, Maclusky I. Pediatric long-term home mechanical ventilation: twenty years of follow-up from one Canadian center. Pediatr Pulmonol 2013. doi:10.1002/ppul.22868. Most recent publication describing the largest reported pediatric long-term mechanical ventilation followed over two decades in the Home Ventilation Program at The Hospital for Sick Children, Toronto (Sickkids), Canada.

2. Gregoretti C, Ottonello G, Testa MBC, Mastella C, Rava L, Bignamini E, Veljkovic A, Cutrera R. Survival of patients with spinal muscular atrophy type 1. Pediatrics. 2013;131(5):e1509-14.

3. Cristea AI, Carroll AE, Davis SD, Swigonski NL, Ackerman VL. Outcomes of children with severe bronchopulmonary dysplasia who were ventilator dependent at home. Pediatrics. 2013;132(3): e727-34.

4. Murphy J. Medically stable children in PICU: better at home. Paediatr Nurs. 2008;20(1):14-6.

5. Craven DE, Lei Y, Ruthazer R, Sarwar A, Hudcova J. Incidence and outcomes of ventilator-associated tracheobronchitis and pneumonia. Am J Med. 2013;126(6):542-9.

6. - Edwards EA, Nixon GM. Paediatric home ventilatory support: changing milieu, proactive solutions. J Paediatr Child Health 2013;49(1):13-18. This paper provides information on variable levels of support for care at home for children on long-term mechanical ventilation in Australia and New Zealand.

7. Edwards JD, Kun SS, Keens TG. Outcomes and causes of death in children on home mechanical ventilation via tracheostomy: an institutional and literature review. J Pediatr. 2010;157(6): 955-959 e952.

8. Gowans M, Keenan HT, Bratton SL. The population prevalence of children receiving invasive home ventilation in Utah. Pediatr Pulmonol. 2007;42(3):231-6.

9. Noyes J, Godfrey C, Beecham J. Resource use and service costs for ventilator-dependent children and young people in the UK. Health Soc Care Commun. 2006;14(6):508-22.

10. - Wallis C, Paton JY, Beaton S, Jardine E. Children on long-term ventilatory support: 10 years of progress. Arch Dis Child 2011;96(11):998-1002. This report provides data of children on long-term mechanical ventilation in $U K$.

11. Kingston RL. Home care of the ventilator dependent child. Home Health Care Manag Pract. 2007;19(6):436-41.

12. Ottonello G, Mastella C, Franceschi A, Bosticco D, Wolfler A, Pedemonte M, Esposito I, Gregoretti C. Spinal muscular atrophy type 1: avoidance of hospitalization by respiratory muscle support. Am J Phys Med Rehabil. 2011;90(11):895-900.

13. Gilgoff RL, Gilgoff IS. Long-term follow-up of home mechanical ventilation in young children with spinal cord injury and neuromuscular conditions. J Pediatr. 2003;142(5):476-80.
14. Young HK, Lowe A, Fitzgerald DA, Seton C, Waters KA, Kenny E, Hynan LS, Iannaccone ST, North KN, Ryan MM. Outcome of noninvasive ventilation in children with neuromuscular disease. Neurology. 2007;68(3):198-201.

15. Com G, Kuo DZ, Bauer ML, Lenker CV, Melguizo-Castro MM, Nick TG, Makris CM. Outcomes of children treated with tracheostomy and positive-pressure ventilation at home. Clin Pediatr (Phila). 2013;52(1):54-61.

16. Paulides FM, Plotz FB, Verweij-van den Oudenrijn LP, van Gestel JP, Kampelmacher MJ. Thirty years of home mechanical ventilation in children: escalating need for pediatric intensive care beds. Intensive Care Med. 2012;38(5):847-52.

17. • Smith H, Hilliard T. Organizing home ventilation. Paediatr Child Health 2010;21(5):224-9. This is a useful and practical paper from the UK explaining how to send children on mechanical ventilation back home effectively.

18. Burr BH, Guyer B, Todres ID, Abrahams B, Chiodo T. Home care for children on respirators. $N$ Engl $J$ Med. 1983;309(21):1319-23.

19. Palfrey JS, Haynie M, Porter S, Fenton T, Cooperman-Vincent P, Shaw D, Johnson B, Bierle T, Walker DK. Prevalence of medical technology assistance among children in Massachusetts in 1987 and 1990. Public Health Rep. 1994;109(2):226-33.

20. Graham RJ, Fleegler EW, Robinson WM. Chronic ventilator need in the community: a 2005 pediatric census of Massachusetts. Pediatrics. 2007;119(6):e1280-7.

21. Tibballs J, Henning R, Robertson CF, Massie J, Hochmann M, Carter B, Osborne A, Stephens RA, Scoble M, Jones SE, White J, Bryan D. A home respiratory support programme for children by parents and layperson carers. J Paediatr Child Health. 2010;46(1-2):57-62.

22. Racca F, Berta G, Sequi M, Bignamini E, Capello E, Cutrera R, Ottonello G, Ranieri VM, Salvo I, Testa R, Wolfler A, Bonati M. Long-term home ventilation of children in Italy: a national survey. Pediatr Pulmonol. 2011;46(6):566-72.

23. Sakakihara Y, Yamanaka T, Kajii M, Kamoshita S. Long-term ventilator-assisted children in Japan: a national survey. Acta Paediatr Jpn. 1996;38(2):137-42.

24. Edwards EA, Hsiao K, Nixon GM. Paediatric home ventilatory support: the Auckland experience. J Paediatr Child Health. 2005;41(12):652-8.

25. Downes JJ, Boroughs DS, Dougherty J, Parra M. A statewide program for home care of children with chronic respiratory failure. Caring 2007;26(9):16-18, 20, 22-13 passim.

26. Preutthipan A. Home care and mechanical ventilation for children in Thailand. IVUN's Int Vent Users Netw Vent Assist Living. 2000;14(1):2-4.

27. Hsia SH, Lin JJ, Huang IA, Wu CT. Outcome of long-term mechanical ventilation support in children. Pediatr Neonatol. 2012;53(5):304-8.

28. McDougall CM, Adderley RJ, Wensley DF, Seear MD. Longterm ventilation in children: longitudinal trends and outcomes. Arch Dis Child. 2013;98(9):660-5.

29. Goodwin S, Smith H, Hewer SL, Fleming P, Henderson AJ, Hilliard T, Fraser J. Increasing prevalence of domiciliary ventilation: changes in service demand and provision in the South West of the UK. Eur J Pediatr. 2011;170(9):1187-92.

30. Ottonello G, Ferrari I, Pirroddi IM, Diana MC, Villa G, Nahum L, Tuo P, Moscatelli A, Silvestri G. Home mechanical ventilation in children: retrospective survey of a pediatric population. Pediatr Int. 2007;49(6):801-5.

31. Amin RS, Fitton CM. Tracheostomy and home ventilation in children. Semin Neonatol. 2003;8(2):127-35.

32. Nixon GM, Edwards EA, Cooper DM, Fitzgerald DA, Harris M, Martin J, Massie RJ, Suresh S, Waters KA, Wilson A. Ventilatory support at home for children. A Consensus Statement from the 
Australasian Paediatric Respiratory Group, February 2008. http:// www.thoracic.org.au/documents/papers/aprghomeventilationguide line.pdf. Accessed 13 Dec 2013.

33. Hull J, Aniapravan R, Chan E, Chatwin M, Forton J, Gallagher J, Gibson N, Gordon J, Hughes I, McCulloch R, Russell RR, Simonds A. British Thoracic Society guideline for respiratory management of children with neuromuscular weakness. Thorax. 2012;67(Suppl 1):i1-40.

34. Simonds AK, Ward S, Heather S, Bush A, Muntoni F. Outcome of paediatric domiciliary mask ventilation in neuromuscular and skeletal disease. Eur Respir J. 2000;16(3):476-81.

35. Pavone M, Verrillo E, Caldarelli V, Ullmann N, Cutrera R. Noninvasive positive pressure ventilation in children. Early Hum Dev. 2013;89:S25-31.

36. Boldrini R, Fasano L, Nava S. Noninvasive mechanical ventilation. Curr Opin Crit Care. 2012;18(1):48-53.

37. Piper A. Discharge planning and management for patients with chronic respiratory failure using home mechanical ventilation. Breathe. 2010;6(4):323-33.

38. Teschler H, Stampa J, Ragette R, Konietzko N, Berthon-Jones M. Effect of mouth leak on effectiveness of nasal bilevel ventilatory assistance and sleep architecture. Eur Respir J. 1999;14(6): 1251-7.

39. Willson GN, Piper AJ, Norman M, Chaseling WG, Milross MA, Collins ER, Grunstein RR. Nasal versus full face mask for noninvasive ventilation in chronic respiratory failure. Eur Respir J. 2004;23(4):605-9.

40. • Berry RB, Chediak A, Brown LK, Finder J, Gozal D, Iber C, Kushida CA, Morgenthaler T, Rowley JA, Davidson-Ward SL. Best clinical practices for the sleep center adjustment of noninvasive positive pressure ventilation (NPPV) in stable chronic alveolar hypoventilation syndromes. J Clin Sleep Med 2010;6(5):491-509. This is a very helpful guideline on how to adjust noninvasive ventilation, particularly under polysomnography.

41. AARC (American Association for Respiratory Care) clinical practice guideline. Long-term invasive mechanical ventilation in the home. Respir Care 1995;40(12):1313-20.

42. Home Care. http://enwikipediaorg/wiki/Home_care. Accessed 24 Sept 2013.
43. Paying for Healthcare at Home. http://www.hahcouk/for-patientsand-carers/being-a-patient/paying-for-healthcare-at-home. Accessed 24 Sept 2013.

44. Health in Thailand. http://enwikipediaorg/wiki/Health_in_ Thailand. Accessed 24 Sept 2013.

45. AARC Clinical Practice Guideline. Long-term invasive mechanical ventilation in the home: 2007 revision \& update. Respir Care. 2007;52(8):1056-62.

46. •• McKim DA, Road J, Avendano M, Abdool S, Cote F, Duguid N, Fraser J, Maltais F, Morrison DL, O'Connell C, Petrof BJ, Rimmer K, Skomro R. Home mechanical ventilation: a Canadian Thoracic Society clinical practice guideline. Can Respir J 2011;18(4):197-15. Updated guideline and comprehensive review of home ventilation in Canada, mainly for the adult population.

47. Tearl DK, Hertzog JH. Home discharge of technology-dependent children: evaluation of a respiratory-therapist driven family education program. Respir Care. 2007;52(2):171-6.

48. Chatwin M, Heather S, Hanak A, Polkey MI, Simonds AK. Analysis of home support and ventilator malfunction in 1,211 ventilator-dependent patients. Eur Respir J. 2010;35(2):310-6.

49. Carnevale FA, Alexander E, Davis M, Rennick J, Troini R. Daily living with distress and enrichment: the moral experience of families with ventilator-assisted children at home. Pediatrics. 2006;117(1):e48-60.

50. Kirk S, Glendinning C, Callery P. Parent or nurse? The experience of being the parent of a technology-dependent child. J Adv Nurs. 2005;51(5):456-64.

51. Heaton J, Noyes J, Sloper P, Shah R. Families' experiences of caring for technology-dependent children: a temporal perspective. Health Soc Care Commun. 2005;13(5):441-50.

52. Mah JK, Thannhauser JE, McNeil DA, Dewey D. Being the lifeline: the parent experience of caring for a child with neuromuscular disease on home mechanical ventilation. Neuromuscul Disord. 2008;18(12):983-8.

53. Jardine E, O'Toole M, Paton JY, Wallis C. Current status of long term ventilation of children in the United Kingdom: questionnaire survey. Br Med J. 1999;318(7179):295-9. 